\title{
Spatial and Temporal Variability of Thermal Stress to China's Coral Reefs in South China Sea
}

\author{
ZUO Xiuling $^{1,2}$, SU Fenzhen ${ }^{1}$, WU Wenzhou ${ }^{1,2}$, CHEN Zhike ${ }^{3}$, SHI Wei ${ }^{1}$ \\ (1. State Key Laboratory of Resources and Environmental Information System, Institute of Geographic Sciences and Natural Resources \\ Research, Chinese Academy of Sciences, Beijing 100101, China; 2. University of Chinese Academy of Sciences, Beijing 100049, China; \\ 3. Heilongjiang Agricultural Reclamation Survey, Design and Research Institute, Harbin 150090, China)
}

\begin{abstract}
Coral bleaching, caused by elevated sea surface temperature (SST), is occurring more frequently and seriously worldwide. Due to the lack of field observations, we understand little about the large-scale variability of thermal stress in the South China Sea (SCS) and its effect on China's coral reefs. This paper used 4-km high resolution gap-filled SST (FilledSST) data and thermal stress data related to coral bleaching derived from Coral Reef Temperature Anomaly Database (CoRTAD) to quantify the spatial and temporal characteristics of chronic thermal stress and acute thermal stress to China's coral reefs in SCS from 1982 to 2009 . We analyzed the trend of SST in summer and the thermal stress frequency, intensity and duration during this period. The results indicate that, as a chronic thermal stress, summer mean SST in SCS shows an average upward trend of $0.2^{\circ} \mathrm{C} /$ decade and the spatial pattern is heterogeneous. Waters of Xisha Islands and Dongsha Islands of the northern SCS are warming faster through time compared to Zhongsha Islands and Nansha Islands sea areas of the southern SCS. High frequency bleaching related thermal stress events for these reefs are seen in the area to the northwest of Luzon Island. Severe anomaly thermal stress events are more likely to occur during the subsequent year of the El Niño year for these coral reefs. Besides, the duration of thermal stress varies considerably by anomaly year and by region.
\end{abstract}

Keywords: coral reef; sea surface temperature (SST); thermal stress; El Niño-Southern Oscillation (ENSO); South China Sea (SCS)

Citation: Zuo Xiuling, Su Fenzhen, Wu Wenzhou, Chen Zhike, Shi Wei, 2015. Spatial and temporal variability of thermal stress to China's coral reefs in South China Sea. Chinese Geographical Science, 25(2): 159-173. doi: 10.1007/s11769-015-0741-6

\section{Introduction}

Coral reef ecosystems are particularly sensitive to the climate related environment. Increasing and abnormal sea surface temperature (SST), also called chronic thermal stress and acute thermal stress, has been recognized as the most extensive and threatening stress faced by coral reefs. A detrimentally impact related to SST increasing is mass coral bleaching, a loss of the zooxanthellae living within the coral tissue (Hoegh-Guldberg, 1999). As zooxanthellae supply the host corals with most of its nutritional requirements, prolonged or particularly severe bleaching often results in partial or complete coral mortality. Global warming as a direct consequence of anthropogenic $\mathrm{CO}_{2}$ emissions is a kind of chronic stress and a rise in regional SST of $0.1^{\circ} \mathrm{C}$ leads to $35 \%$ and $42 \%$ increases in the geographic extent and intensity of Caribbean's coral bleaching, respectively (McWilliams et al., 2005). Mass coral bleaching of 1997/1998 induced by abnormal climate of strong El Niño-Southern Oscillation (ENSO) was a catastrophic event as an acute stress, not only the most geographically extensive but also the most severe on record since 1880, with bleaching reports nearly all over the world (Hoegh-Guldberg, 1999; Goreau et al., 2000; Lough, 2000). Besides, a significant relationship also

Received date: 2014-05-12; accepted date: 2014-08-26

Foundation item: Under the auspices of National High Technology Research and Development Program of China (No. 2012AA12A406) Corresponding author: SU Fenzhen. E-mail: sufz@1reis.ac.cn

(C) Science Press, Northeast Institute of Geography and Agroecology, CAS and Springer-Verlag Berlin Heidelberg 2015 
exists between warm temperature anomalies and coral disease outbreaks (Heron et al., 2010; Aeby et al., 2011; Lough, 2012; Ferreira et al., 2013). Coral embryonic development, survivorship, larval settlement as well as growth and calcification of coral taxa are also negatively affected by elevated temperatures (Worum et al., 2007; Randall and Szmant, 2009; Carricart-Ganivet et al., 2012; Chen et al., 2013). Anthropogenically local environment stressors play a role in accelerating this threat (Carilli et al., 2010; Negri and Hoogenboom, 2011; Negri et al., 2011; Chang et al., 2012; Shang and Bai, 2012; Hongo and Yamano, 2013). As a result, significant researches involving several fields have focused on the causes of thermal stress and their effects on coral reefs.

The South China Sea (SCS), situated between the Karimata Strait $\left(\sim 3^{\circ} \mathrm{S}\right)$ and the middle of the Taiwan Strait $\left(\sim 23.5^{\circ} \mathrm{N}\right)$, is the largest marginal sea in the southeastern Asia. Climate here not only shows significant seasonal variability under the influence of East Asian monsoon system, but also reveals obvious interannual variability as a tropical Pacific marginal sea (Fang et al., 2006). Under this climate conditions, it possesses numerous fringing reefs and offshore reefs while reefs owning to China, including the disputed coral reefs claimed by up to six countries (Morton and Blackmore, 2001), are totally about $30000 \mathrm{~km}^{2}$ (Hughes et al., 2012; Zhang et al., 2012). These reefs of China are great natural assets as they supply large numbers of people with goods and services such as fish, tourism, coastal protection as well as the important ecological values (Moberg and Folke, 1999; Burke et al., 2006; Ma, 2012). Adjacent to the Coral Triangle, which is the global center of the highest coastal marine biodiversity (Allen and Werner, 2002), these reefs especially the largest offshore Nansha Islands have high biodiversity and annual fisheries production is about $3.0 \times 10^{7} \mathrm{t}$ (Burke et al., 2006). Fish, coral larvae going from Nansha Islands to surrounding damaged reefs through current have made great contribution to the ecosystem sustainability in SCS (Burke et al., 2006).

In contrast to its rich resources, China has contributed far less to the coral reef studies of the world than other countries. The researchers of coral reefs in China are increasing until recent years (Hughes et al., 2012), and the relations between environment and coral reefs are of great concern, such as temperature (Yu et al., 2004; Yu,
2012; Chen et al., 2013). Given the inaccessibility of the offshore reefs, most of the recent investigations are conducted on some coastal fringing reefs near Hainan Island and some other locations along the Chinese mainland (Hughes et al., 2012) based on experiments. However, how climate changes in recent decades in the SCS affected these reefs over space and time is nearly unknown. There was even no relative bleaching report from the mainland of China during the mass coral bleaching event of 1997/1998. Nonetheless, the few bleaching reports are more likely due to the lack of observers, rather than an absence of bleaching. Reefs near Philippines such as the northern Palawan Islands $\left(10^{\circ} 24^{\prime}-11^{\circ} 38^{\prime} \mathrm{N}, 119^{\circ} 10^{\prime}-120^{\circ} 30^{\prime} \mathrm{E}\right)$ and Bolinao $\left(16^{\circ} 22^{\prime}-\right.$ $\left.16^{\circ} 27^{\prime} \mathrm{N}, 119^{\circ} 52^{\prime}-119^{\circ} 59^{\prime} \mathrm{E}\right)$ experienced vast area bleaching in 1998 (Arceo et al., 2001), indicating coral reefs of China may also have suffered from this extreme thermal event. Then in June 2007, in situ data found the initial stage of coral bleaching on Zhubi Reef and Meiji Reef (Li et al., 2011) of the Nansha Islands due to abnormally high temperatures. In addition, coral records show that coral reefs in the southern SCS have experienced frequent bleaching events due to elevated SST over the last 200 years (Yu, 2012). As coral abundance in China has declined rapidly during the past 10-30 years under human disturbances (Hughes et al., 2012; $\mathrm{Yu}, 2012)$, the SST increasing and predicted coral bleaching in the coming decades (Meissner et al., 2012; IPCC, 2013) will make these reefs' status even worse. Destruction of these reefs may affect the whole ecosystem and reef health in the SCS. It is important to investigate the spatio-temporal patterns of thermal stress for coral reefs in China in the SCS because it can lay foundation for multiple purposes, including investigation of coral health, monitoring of coral bleaching and conservation of these reefs under climate change.

The large-scale thermal stress prediction system developed by the National Oceanic and Atmospheric Administration's (NOAA)-Coral Reef Watch (CRW) based on the NOAA $0.5^{\circ}$ (about $50 \mathrm{~km}$ ) resolution Advanced Very High Resolution Radiometer(AVHRR) twice-weekly nighttime-only SST product has proven effective at indentifying the occurrence of coral bleaching worldwide (Liu et al., 2003). However, the spatial patterns of coral bleaching can be relatively heterogeneous. These events can be quite localized and cluster over scales of $10 \mathrm{~km}$ or less (Berkelmans et al., 2004; Selig et al., 2010). 
Therefore, coarse-scale $50-\mathrm{km}$ resolution satellite products of NOAA-CRW have failed to detect these localized bleaching events and improved higher resolution can be more accurate to forecast bleaching (Weeks et al., 2008). Selig et al. (2010) created a 4-km resolution Coral Reef Temperature Anomaly Database (CoRTAD) and used thermal stress anomaly (TSA) metric related to coral bleaching to characterize the global patterns of ocean temperature anomalies during the period of 1985-2005. TSA data are produced based on the previous analysis that sea temperature of $1{ }^{\circ} \mathrm{C}$ warmer than the mean summer maxima can trigger the syndrome of coral bleaching (Glynn, 1993). However, TSA values can measure the intensity of the thermal stress, but do not measure the cumulative effects of thermal stress to coral reefs (Liu et al., 2003), such as mild beaching and severe bleaching. Besides, the study of Selig et al. (2010) was focused on coral reefs worldwide and lacked a detailed analysis of thermal stress in the SCS. Here, we utilized 4-km high resolution gap-filled SST (FilledSST) data and coral bleaching related metric data derived from CoRTAD to implement a detailed spatio-temporal analysis of thermal stress to coral reefs in China in the SCS from 1982 to 2009. Our objects are to identify the variability of thermal stress in SCS and its potential effect to China's coral reefs. We quantified the upward trend of chronic thermal stress and the thermal stress frequency, intensity and duration to China's coral reefs during this period.

\section{Materials and Methods}

\subsection{Study area}

The study area of this paper $\left(3^{\circ}-23^{\circ} \mathrm{N}, 109^{\circ}-121^{\circ} \mathrm{E}\right)$ was four offshore archipelagos and the fringing reefs of China in SCS, including Xisha Islands (Paracel Islands), Zhongsha Islands (Macclesfield Bank), Dongsha Islands (Pratas Islands), Nansha Islands (Spratly Islands), and the fringing reefs of Guangdong, Hong Kong, Hainan and Taiwan in China in SCS (Fig. 1). In order to analyze the results from a macro perspective, our analysis was based on the whole SCS and then focused on these reefs.

Four offshore archipelagos are the most important offshore system of the SCS. Reefs here have an atolllike structure including complex atolls, simple atolls and table reefs. Xisha Islands comprise $\sim 36$ reefs. Between 23 and 127 species and subspecies in 37-38 genera of scleractinian corals have been recorded in the Xisha Islands (Morton and Blackmore, 2001). Zhongsha Islands comprise $>20$ atolls and islets and coral diversity here is lower than that in the Xisha Islands as most of the reefs are located $\sim 7 \mathrm{~m}$ below the surface. Dongsha Islands have an area of $100 \mathrm{~km}^{2}$ and the Dongsha Atoll itself covers an area of $1.7 \mathrm{~km}^{2}$ with the small Dongsha Island situated on its western edge. A total of 101 species of corals have been recorded in Dongsha Islands (Dai et al., 1995). The vast area of Nansha Islands is known to navigators as the dangerous grounds including many submerged hills and plateau. It comprises more than 230 islands, cays, submerged reefs and shoals. Coral communities flourish here and they vary considerably with a high percentage cover. Over 200 species in 50 genera of scleractinian corals have been recorded in Nansha Islands, nearly one third of the Indo-Pacific scleractinian species (Fu et al., 2009). McManus (1994) considered that the Nansha Islands constitute one of the most biodiverse areas of the World's seas.

Coral structures range from simple non-reef-building coral communities along the continental coast of southern China, e.g., Hong Kong, to the fringing reefs around Hainan. The reefs on the southern and southeastern coasts of Hainan are considered to be younger than 10000 years old and are less than 10-m thick. At present, only scattered coral colonies survive yet some 166 species in 43 genera of scleractinian corals have been recorded from Hainan and associated islands although there is a more conservative estimate of 110 species and subspecies in 34 genera (Morton and Blackmore, 2001). Besides, reefs are mainly distributed in the southern Taiwan of China. It is encircled by well-developed fringing reefs inhabited by considerable coral fauna. Over 280 species of scleractinians have been described in the seas of southern Taiwan (Dai, 2010).

\subsection{Data used}

Location data for coral reefs were compiled from two datasets. The offshore reefs were derived from Reef Archive of China while the fringing reefs were from reef base website (http://reefgis.reefbase.org/). Data from the two sources are all points.

Weekly FilledSST from 1982 to 2009 were obtained from CoRTAD (Selig et al., 2010) to analyze the general climate environment of these coral reefs and the trend in SST in summer during this period. Currently, 


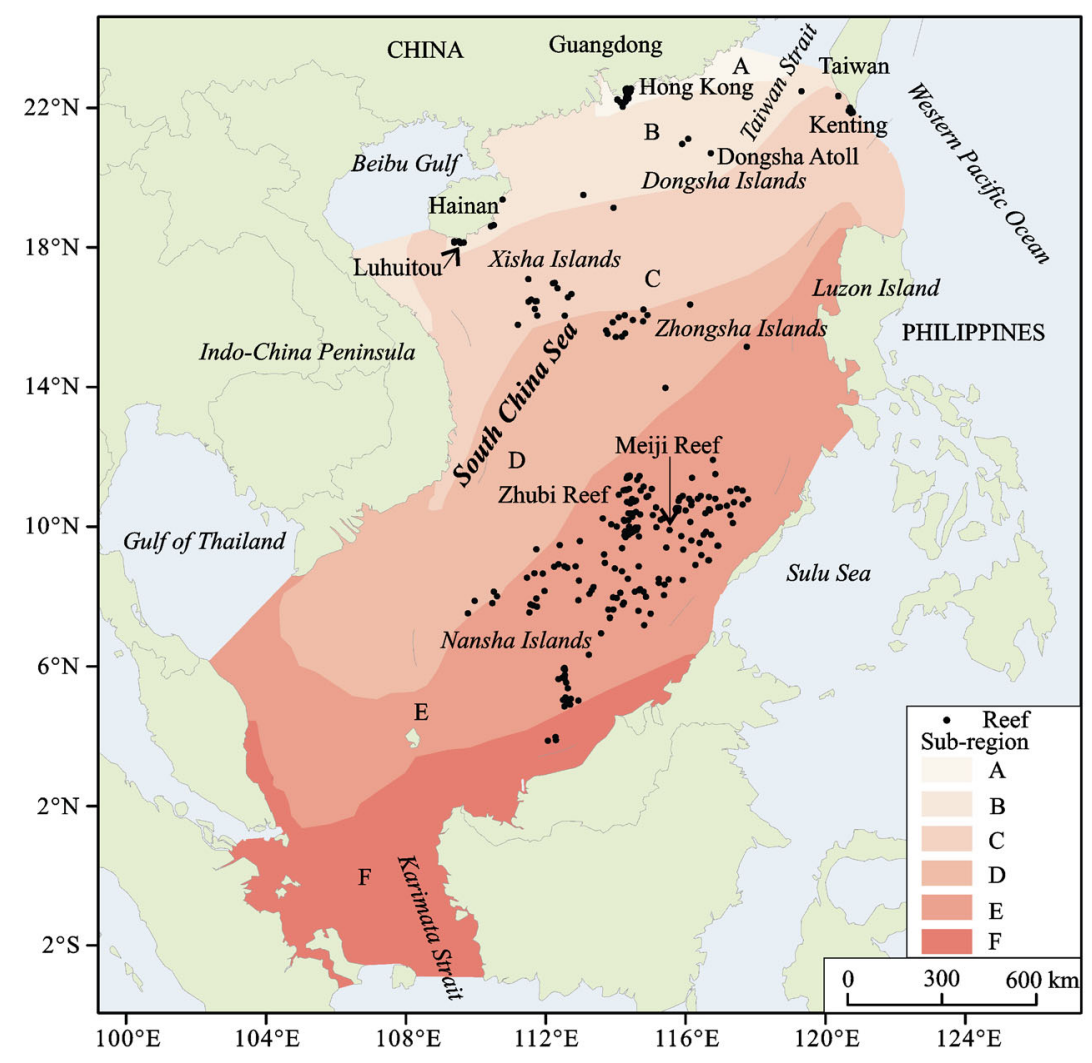

Fig. 1 Map of South China Sea (SCS) divided into six sub-regions (A, B, C, D, E, F) and coral reefs in study area

nighttime-only SST acquired by satellite is the standard for coral researchers to represent the temperatures of corals at depth, such as the thermal stress products of NOAA-CRW. CoRTAD is a day-night average database, using Pathfinder Version 5.0 data (Casey et al., 2010) derived from the AVHRR sensor series, with approximately $4-\mathrm{km}$ resolution. FilledSST data in the CoRTAD produced after a $3 \times 3$ pixels median spatial fill and a fill of piecewise cubic Hermite interpolating polynomial (PCHIP) function are accurate compared with in situ loggers over vast areas of coral locations and water depths at least $10 \mathrm{~m}$. The overall mean difference between the average of nighttime-only data and CoRTAD data when compared with in situ loggers was less than $0.05^{\circ} \mathrm{C}$. Besides, validation suggested that CoRTAD data reduce the need for interpolations compared with the nighttime-only data, which could make a difference in some places (Selig et al., 2010). At the time of the study, these data covered the longest continuous time series (1982-2009) of SSTs and indices indicative of thermal stress on coral reefs. As offshore reefs have less human disturbances, SST derived by satellite on these reefs can reflect the natural climate change more accurately than on fringing reefs.
TSA and TSA degree heating weeks (TSA_DHW) data of CoRTAD were used to assess the frequency, intensity and duration of the thermal stress occurred from 1982 to 2009. TSA index provides a measure of the current intensity of thermal stress for a given location. It is produced based on the method that weekly FilledSST minus SST of the maximum climatological week (the warmest week of the 52 climatological weeks averaged from 1985 to 2005) (Selig et al., 2010), which is also the positive anomalies from typical summertime temperatures to which corals are currently adapted or acclimatized (Glynn, 1993; Podestá and Glynn, 2001; Liu et al., 2003). While prolonged thermal stress can result in coral bleaching, Liu et al. (2003) developed the 'Degree Heating Weeks' (DHW) index to measure the cumulative thermal stress by accumulating weekly temperature anomalies of at least $1{ }^{\circ} \mathrm{C}$ above the maximum of the monthly mean SST climatology over a running 12-week period. The index expresses in ${ }^{\circ} \mathrm{C}$-weeks. Therefore, TSA_DHW data are calculated over a running 12-week period by accumulating TSA values greater than or equal to 1 to represent the accumulation of thermal stress for a given pixel. One TSA_DHW is equivalent to TSA levels staying at $1{ }^{\circ} \mathrm{C}$ for one week, or 
TSA levels staying at $2^{\circ} \mathrm{C}$ for half a week, and so forth.

\subsection{Climatological sea surface temperature (SST) of coral reef environment}

Annual minimum, annual mean and annual maximum of SST for each pixel were calculated from weekly FilledSST data to reflect the reefs' climate characteristics. A spatial clustering of k-means algorithm (Arthur and Vassilvitskii, 2007) then was run on the monthly means of SST data calculated from weekly FilledSST data, grouping pixels of the SCS with similar climatological conditions. Annual SST minimums, annual SST means, annual SST maximums, as well as the climatological SST monthly means from January to December were also calculated for all sub-regions divided to analyze the local climate environments.

The pixel-by-pixel trend of SST change in summer in SCS was estimated by fitting a linear regression method to the summer mean SST of each year calculated from the 4-km weekly FilledSST data. Bleaching tends to occur only in summertime as temperatures are rarely greater than the long-term average warmest week at any other time of a year (Selig et al., 2010). Consequently, the warming rate of SST in summer is important, which can more represent the chronic thermal stress currently faced by coral reefs in the study area.

\subsection{Thermal stress analysis}

Early studies have found that bleaching is predicted to start occurring when a threshold of $1{ }^{\circ} \mathrm{C}$ greater than the typical regional warm season maxima is accumulated for more than 4 weeks (Goreau and Hayes, 1994; Toscano et al., 2000). Satellite products of NOAA-CRW use the DHW metric to predict bleaching events (Liu et al., 2003). Comparison of DHW metric with observed bleaching events suggests that bleaching tends to occur when the DHW reaches $4^{\circ} \mathrm{C}$-weeks and widespread bleaching with some mortality can be expected to happen when DHW reaches $8^{\circ} \mathrm{C}$-weeks. These two thresholds have been incorporated into studies to estimate the bleaching-level thermal stress and are also used into the future modeling of coral bleaching (Liu et al., 2003; Peñaflor et al., 2009; Logan et al., 2014). Here, DHW of $4{ }^{\circ} \mathrm{C}$-weeks and $8^{\circ} \mathrm{C}$-weeks were used as a reference for potential mild bleaching and potential severe bleaching in SCS to estimate the thermal stress frequency, intensity and duration in this study.
Firstly, the thermal stress levels in this analysis were calculated by determining the maximum TSA_DHW of the pixel within a year. The per-pixel thermal stress frequencies during the period 1982-2009 at the mild bleaching level and at the severe bleaching level, on the other hand, were calculated by counting the number of years that there were events when the conditions of $4^{\circ} \mathrm{C}$-weeks $\leq$ TSA_DHW $<8^{\circ} \mathrm{C}$-weeks and TSA_DHW $\geq 8^{\circ} \mathrm{C}$-weeks were satisfied, respectively. The above frequency maps of two thermal stress levels were partitioned into three defined clusters of statistically homogenous classes (i.e., low, moderate, high) according to the number of years that had each level of thermal stress within 28 years.

Annual intensity of thermal stress was defined as the percentages of coral reefs that experienced each level of thermal stress. Levels of 'thermal stress (regardless of severity)' and 'bleaching' were estimated using TSA $\geq$ $1{ }^{\circ} \mathrm{C}$ and TSA_DHW $\geq 4^{\circ} \mathrm{C}$-weeks, respectively. Intensities of these two levels of thermal stress were calculated based on the annual maximum TSA and TSA_DHW values extracted. In order to understand the bleaching-level thermal stress more clearly, the intensities of mild bleaching-level thermal stress and severe bleaching-level thermal stress were also assessed.

The duration of temperature anomalies has long been recognized to increase mortality from bleaching events (Glynn et al., 1988). Over the 28-year period annual intensity of thermal stress analyzed, anomaly years can be extracted and annual intensity of bleaching-level thermal stress as well as annual duration of thermal stress for sub-regions previously clustered were calculated to analyze the thermal stress distribution. Annual duration of thermal stress was based on the accumulation of weeks of all the anomaly events in a year. The anomaly event was defined as onset when TSA equaled or exceeded the threshold value 1 and subsidence when TSA returned below the threshold (Selig et al., 2010). Annual intensities of bleaching-level thermal stress and annual anomaly durations for sub-regions were only quantified for the anomaly years extracted.

\section{Results and Analyses}

\subsection{Climate conditions of sea surface temperature (SST)}

Six distinct sub-regions of the SCS are shown in Fig. 1 
and coral reefs in the study area occupy all of these clusters. All the clusters stretch a northeast-southwest trend, which is consistent with the Southwest Monsoon in summer and the Northeast Monsoon in winter as well as the flow of Monsoon Current in the SCS. Coral reefs dominate warm and thermally stable oceans, where temperature does not lower than $18^{\circ} \mathrm{C}$ in winter (Kleypas et al., 1999). And the most suitable ocean temperature for coral reefs is generally considered between $25^{\circ} \mathrm{C}$ and $30^{\circ} \mathrm{C}$. In summer, from May to September, under the influence of the Southwest Monsoon and Current, monthly mean SST is between $25{ }^{\circ} \mathrm{C}$ to $31{ }^{\circ} \mathrm{C}$ for sub-regions (Fig. 2), which may reach the thermal thresholds for some physiological processes of coral reef organisms. In winter, from November to next April, SST is lower influenced by the Northeast Monsoon and corals in some sub-regions especially A, where the annual average minimum SST is even below $17^{\circ} \mathrm{C}$ (e.g., 1983-1984) (Fig. 3A), may have the risk of cold stress. Studies have also shown that reefs in the study area tend to occur in region E (Nansha Islands), where there is lower SST variability (Fig. 3E). This distribution is well in line with the typical occurrences of coral reef ecosystems in tropical oceans, where SST variability is within $3.3^{\circ} \mathrm{C}$ range during $80 \%$ of months (Lough, 2012).

Annual mean, maximum and minimum SST of all the sub-regions indicate that the entire region may have experienced a slight increase over 1982-2009 and the year 1998 is outstanding in Fig. 3, when three statistics of SST in most of the sub-regions experienced dramatic increasing. In 1997-1998, mass coral bleaching occurred at every geographic coral-reef realm in the world, resulting in considerable coral mortality (Hoegh-Guldberg, 1999). This most serious event on record was consistent

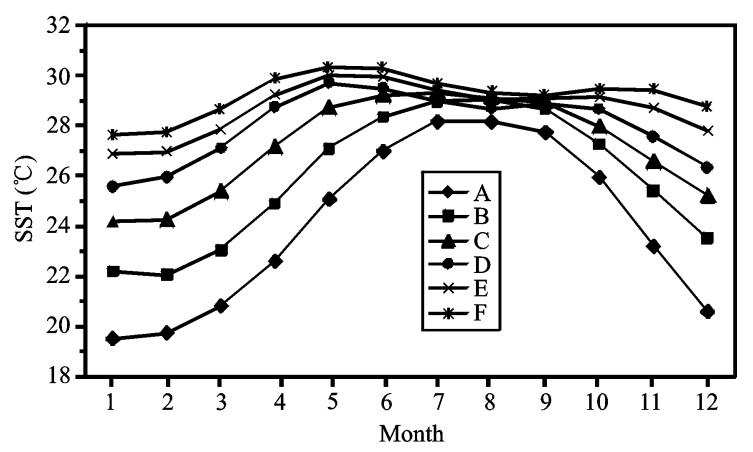

Fig. 2 Monthly mean sea surface temperature (SST) for sub-regions (A-F) during 1982-2009. A-F are shown in Fig. 1 with (by some indices) the disturbance of the strongest ENSO on record (Kerr, 1999). Investigations have found that strong bleaching episodes are consistent with periods of high SST and are correlated with ENSO disturbances. Most occur during strong El Niño periods, but some also occur during strong La Niña periods (Hoegh-Guldberg, 1999). The SCS is also largely influenced by ENSO. Every El Niño event is associated with a SCS positive SST anomaly, while a relative weaker correlation exists between La Niña events and the SCS negative SST anomalies (Klein et al., 1999). Interestingly, maximum SST in summer of 1997 was remarkably low compared to the prominent warming in summer of 1998 (Fig. 3). This seesaw in SST was because of the occurrence of a very strong El Niño in 1997-1998, which altered the local SCS near-surface air temperature, humidity, monsoon wind and the distribution of clouds through the atmospheric bridge of atmospheric circulation changes. The SCS warm anomalies become to appear in the boreal fall of the El Niño year and last for more than one year. A significant feature of the SCS SST anomalies following El Niño is a double peak evolution. Two peaks are reached around February and August of the subsequent year of the El Niño year, respectively. The first peak of SST positive anomalies occurs following the mature phase of El Niño due mainly to the increase of the shortwave radiation and the latent heat flux anomalies, and the center of the maximum SST anomalies occurs in the southern SCS. The second peak of SST warm anomalies in August in the subsequent year of El Niño year is due to the mean meridional geostrophic heat advection and the maximum SST center shifts to the central SCS (Wang et al., 2006). The relative cold in and before August of the El Niño year owns to the increase of the southwest monsoon speed which contributes to the latent heat flux anomalies (Huang et al., 2009). Therefore, in SCS, the contribution of El Niño to the summer SST of El Niño year is a relative cooling effect while to the summer SST during the subsequent year of El Niño year is a warming effect.

The variability of mean SST in summer (May to September) from 1982-2009 within SCS shows the upward trend clearly (Fig. 4). On average, mean SST in summer increases at a rate of $0.2^{\circ} \mathrm{C} /$ decade in SCS during this period and the patterns vary spatially (Fig. 4). SST change ratios are greater than $0.4^{\circ} \mathrm{C} /$ decade in most of coastal waters of SCS. However, this trend needs 

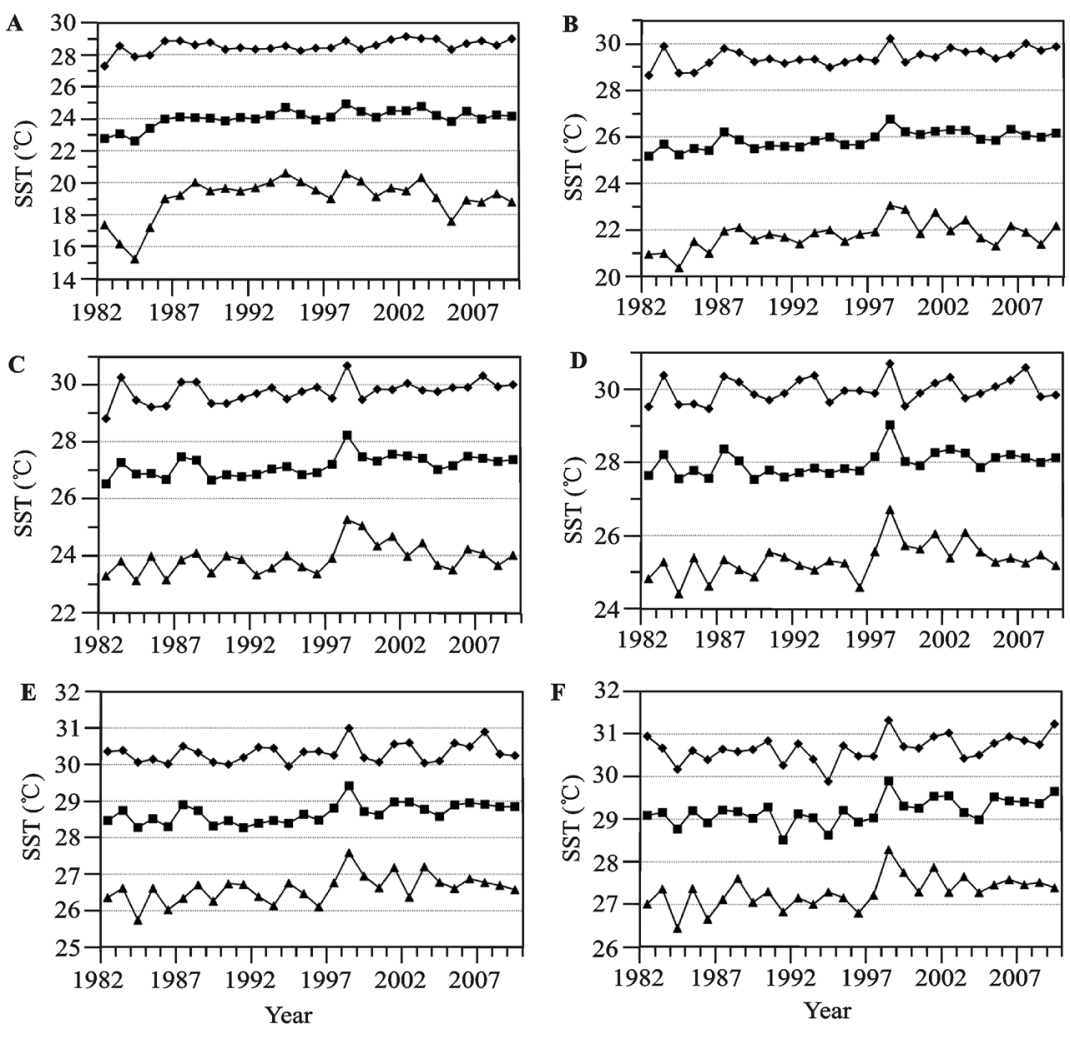

$\rightarrow$ Maximum SST $\rightarrow$ Mean SST $\quad \leftarrow$ Minimum SST

Fig. 3 SST statistics (annual maximum, annual mean, and annual minimum) for each sub-region (A-F) from 1982 to 2009 calculated from 4-km weekly gap-filled sea surface temperature (FilledSST) data in CoRTAD

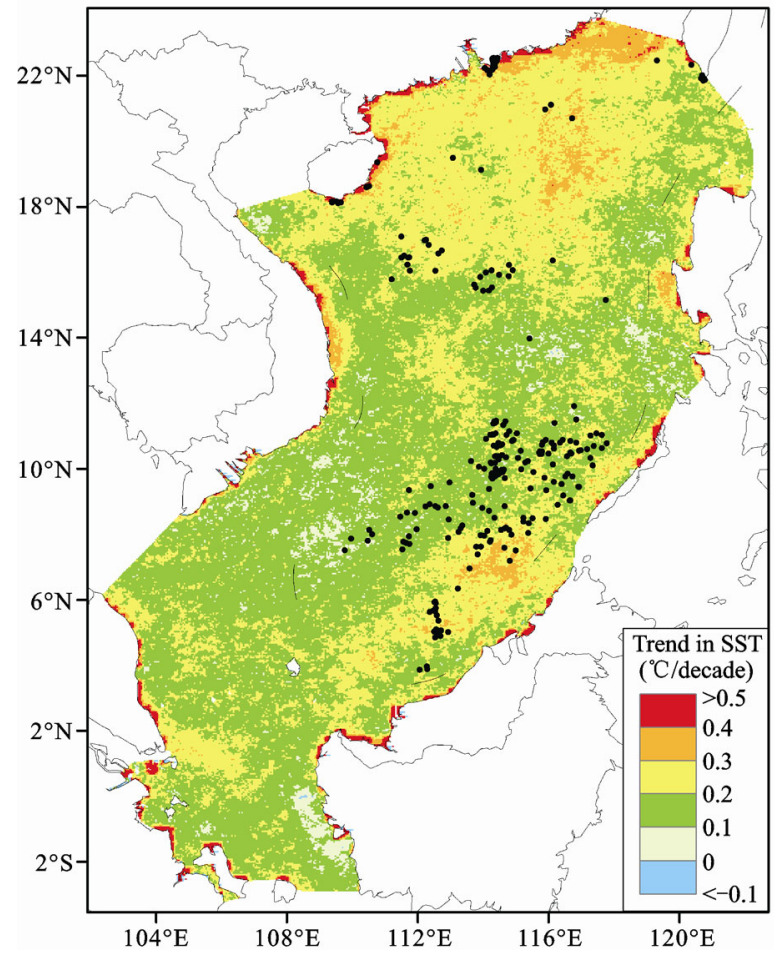

Fig. 4 Trends in mean sea surface temperature (SST) within 4-km pixel in summer (May-September) of SCS during 1982-2009 further analysis as human disturbances (Fig. 4). The waters on the north of Zhongsha Islands sea area have higher warming rates about $0.2-0.3^{\circ} \mathrm{C} /$ decade while the greatest warming regions are surrounding Dongsha Islands and the Taiwan strait, up to $0.3-0.4^{\circ} \mathrm{C} /$ decade (Fig. 4). The southern SCS such as the seas of Zhongsha Islands and Nansha Islands warms slower in summer, about $0.1-0.2^{\circ} \mathrm{C} /$ decade, which is the same with the trend in many other tropical seas (Hoegh-Guldberg, 1999). However, the southern portion of Nansha Islands sea area also shows a higher warming rate like the northern SCS (Fig. 4). Ocean warming is important as it is followed by a warming at reefs (Ferreira et al., 2013). The frequency as well as the intensity of mass bleaching events are predicted to significantly correlate with elevated SST in future (Meissner et al., 2012). Surveys found that bleaching was much less severe at locations that had lower warming rates and greater historical temperature fluctuations during the 2010 large-scale bleaching event in South East Asia (Guest et al., 2012). Sub-regions D-F except the southern part of cluster E 
not only show a lower rate of increase in SST in summer (Fig. 4) but also experience frequent annual fluctuations (Figs. 3D to 3F), indicating that corals in this area may develop the ability of adaptation and acclimatization to the variable local environment. The high fluctuations in temperatures of the southern portion of cluster $\mathrm{E}$ (Fig. 3E) may also help corals to better adapt or acclimate to the rapid increase in SST (Fig. 4). In contrast, corals in clusters of $\mathrm{A}-\mathrm{C}$, which have higher rates of warming (Fig. 4) and lower frequencies of annual variability (Figs. 3A to 3C), will be more susceptible to future bleaching unless they develop ability to cope with the expected fast increase in SST. Aside from coral bleaching, another most significant impact of climate change on coral reefs is ocean acidification due to the increased atmospheric partial pressure of carbon dioxide $\left(\mathrm{pCO}_{2}\right)$, which can lead to lower calcification rates for corals and some other calcifying reef associates (Langdon et al., 2000). However, acidification influences more strongly on coral bleaching than on calcification (Anthony et al., 2008). The paleo-pH records of SCS show a sharp decrease to modern values, which is likely caused by the large amount of anthropogenic $\mathrm{CO}_{2}$ emissions since the period of Industrial Revolution (Liu et $a l .$, 2009). The interaction of acidification with ocean warming may increase the risk of coral bleaching in SCS in future.

\subsection{Anomaly frequency}

An analysis of the frequency of bleaching-level thermal stress during 1982-2009 reveals the SST increases and fluctuations that can cause coral degradation and even mortality (Fig. 5). Mild bleaching-level thermal stress measured by the condition of $4^{\circ} \mathrm{C}$-weeks $\leq$ TSA_DHW $<8^{\circ} \mathrm{C}$-weeks are more concentrated in the area to the northwest of Luzon Island and the area to the southeast of Indo-China Peninsula, about 4 to 10 years. The southernmost SCS appears to have experienced this level of thermal stress for 0 to 2 years, while other seas tend to be about 1 to 5 years (Fig. 5a). Homogeneous frequency areas of mild bleaching-level thermal stress are divided based on number of years of $0-1$ for low frequency, $2-3$ for moderate frequency and $\geq 4$ for high frequency (Fig. 5c). In view of the frequency and the coverage area, on average, there may have been mild bleaching-level thermal stress for 2-3 years in SCS over the period 1982-2009 (Fig. 5c).
Severe bleaching-level thermal stress estimated based on the condition of TSA_DHW $\geq 8^{\circ} \mathrm{C}$-weeks may occur about 2 to 5 years in the area to the northwest of Luzon Island and the area to the southeast of Indo-China Peninsula (Fig. 5b). A severe bleaching-level thermal stress event tends to have occurred in the northern portion of Nansha Islands (Fig. 5b). Fortunately, other seas in most areas may not experience strong anomaly events (Fig. $5 b)$. Homogeneous frequency regions of severe anomaly thermal stress are partitioned based on number of years of 0 for low frequency, of 1 for moderate frequency and of $\geq 2$ for high frequency (Fig. $5 \mathrm{~d}$ ). The average severe bleaching-level thermal stress appears to be less than 1 year in SCS over the period 1982-2009 considering the frequency and the coverage area (Fig. 5d).

High frequency areas of both thermal stress levels in SCS mainly observed in the area to the northwest of Luzon Island and the area to the southeast of Indo-China Peninsula seem to match the greatest warming regions during the second peak of SST warm anomalies in August in the subsequent year of El Niño year (Fang et al. 2006). The area to the northwest of Luzon Island may be the main high frequency area of bleaching related thermal stress for coral reefs in the study area (Fig. 5). Two to three reefs located here seem to have experienced high frequency bleaching-level thermal stress events in these 28 years (Fig. 5). For example, severe bleaching-level thermal stress events are estimated to have occurred on Dongsha Atoll in 1998 and 2007, respectively. A survey in 2001 revealed that severe thermal bleaching in 1998 resulted in mass coral mortality in and out of lagoon of Dongsha Atoll (Soong et al., 2002). By the year 2007, the reefs only showed the status of initial recovery or almost no recovery (Fan et al., 2008a). Unfortunately, another obvious coral bleaching event occurred on Dongsha Atoll due to abnormal high temperatures again in 2007 (Fan et al., 2008b). The agreement on occurrences of severe bleaching events with the TSA_DHW threshold of $8^{\circ} \mathrm{C}$-weeks seems well in SCS. A rapid directional selection may be happened after the extreme thermal event of 1998. On the other hand, corals here may escape recent bleaching as they have experienced such frequent thermal stress events.

Bleaching-level thermal stress seems also a challenge faced by several coastal fringing reefs of Hainan Island and Taiwan, China, if satellite SST data in this paper 
reflect much of the natural climate change in China's coastal seas (Fig. 5). Moderate coral bleaching occurred on Luhuitou fringing reef of Hainan Island in summer of 2010 because of high thermal stress (Li et al., 2012) and coral bleaching was observed on Kenting reef of Taiwan in China during 1997-1998 ENSO event (Wilkinson, 1998), indicating thermal stress actually exists on these coastal reefs. Studies have shown that shallow reefs and inshore reefs are more vulnerable to bleaching (Furby et al., 2013). Changes in SST are of particular concern for
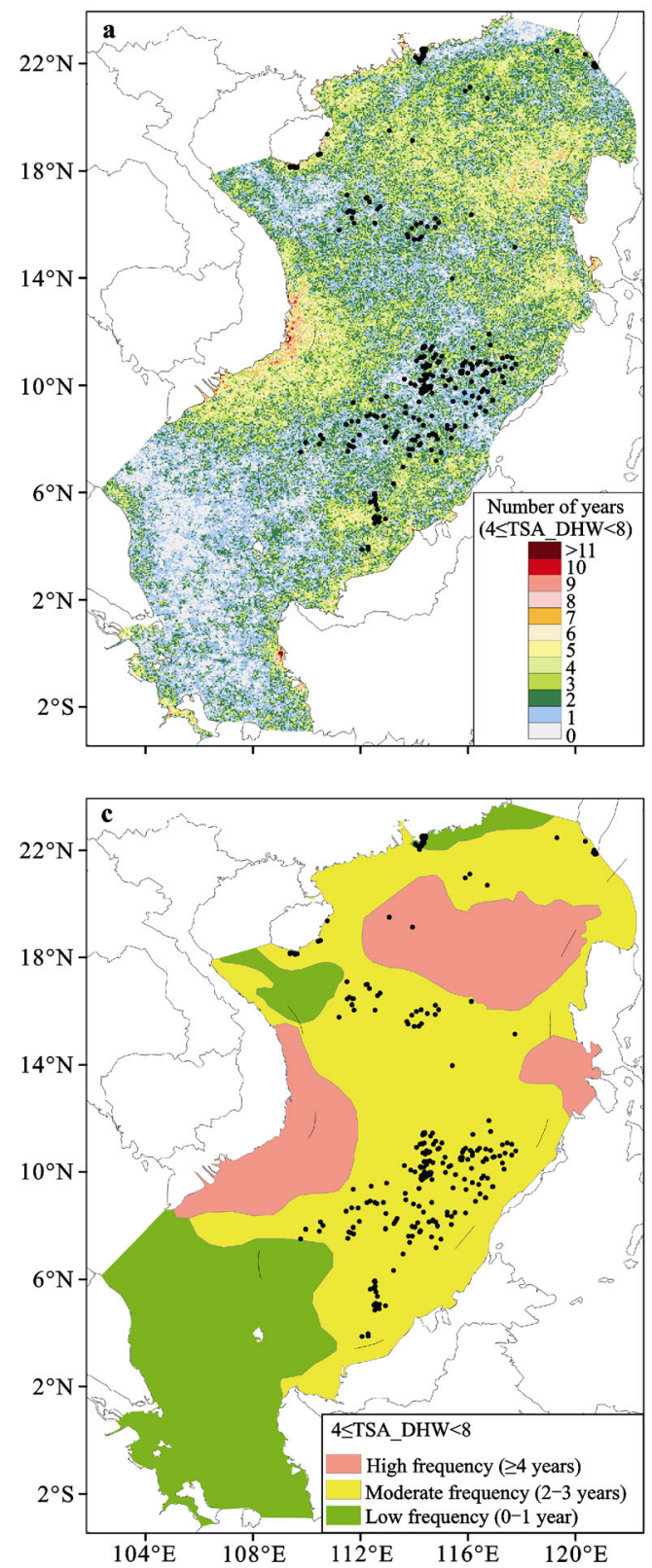

these reefs, especially when additional local anthropologenic stresses exist. Significant local stresses can reduce their resilience to thermal stress (Mora and Ginsburg, 2007; Carilli et al., 2010; Carrigan and Puotinen, 2011; Negri et al., 2011; Negri and Hoogenboom, 2011; Hongo and Yamano, 2013). Over the past 30 years, we have witnessed $80 \%$ decline of coral abundance on coastal fringing reefs of the Chinese mainland and adjoining Hainan Island as a result of human disturbances and global climate warming (Hughes
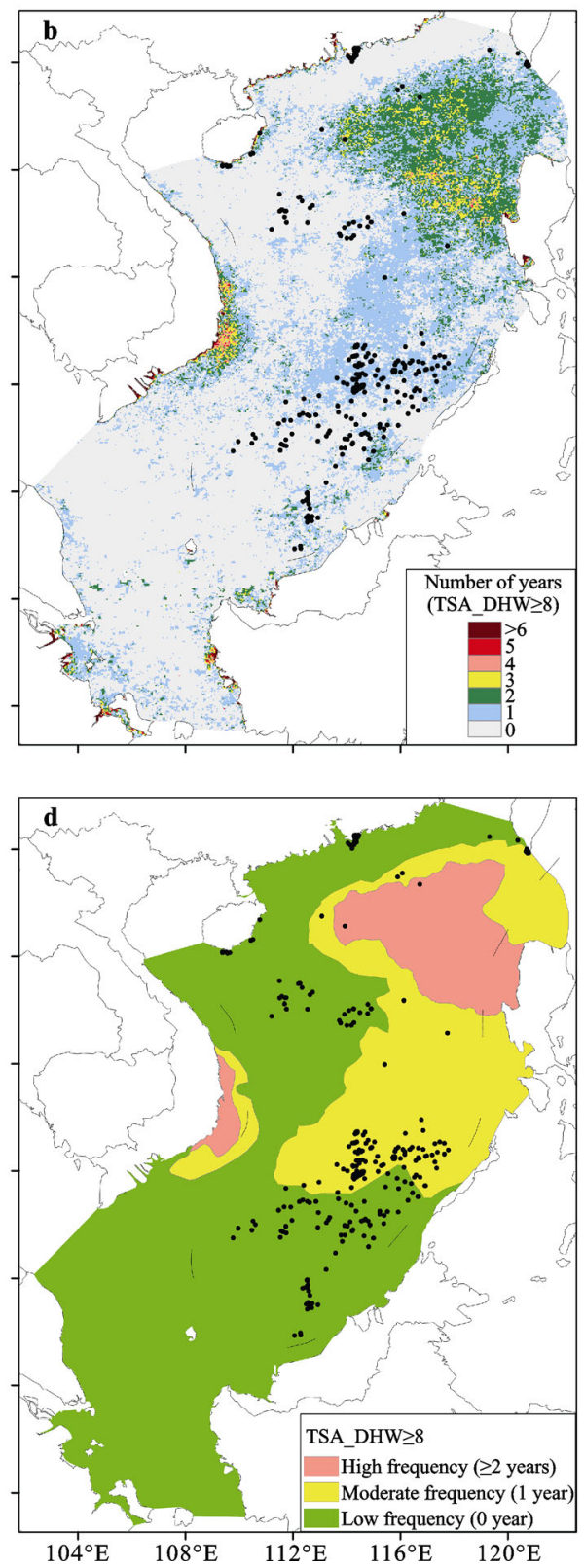

Fig. 5 Frequency maps of thermal stress events during 1982-2009 reaching two thresholds, 4 $\leq$ TSA_DHW $<8$ (a, c) and TSA_DHW $\geq 8$ $(\mathrm{b}, \mathrm{d})$, respectively. Two images (c, d) show three defined low, moderate, high homogenous frequency areas and years defined are shown in bracket after each frequency type 
et al., 2012; Yu, 2012). Local drivers and global drivers may cause rapid deterioration of these reefs unless effective protection and recovery measures can be quickly implemented. Marine reserve or other protective measures to remove chronic anthropogenic disturbance can contribute to the rapid coral recovery (Zhao et al., 2014), so that corals can better cope with the SST increasing in future.

\subsection{Anomaly intensity}

A temporal analysis on TSA and TSA_DHW data was performed for pixels containing coral reefs. Annual intensities of four levels of thermal stress are shown in Fig. 6. Higher intensity of bleaching-level thermal stress is observed in 1996-2009 compared with 1982-1995 (Fig. 6b). The year 1998 is the most unusual year, when $75 \%$ and $66 \%$ reefs are estimated to experience thermal stress (Fig. 6a) and bleaching-level thermal stress (Fig. $6 \mathrm{~b}$ ), respectively. Moreover, the intensity of severe bleaching-level thermal stress was extremely higher in 1998, about 33\% coral reefs estimated to be affected (Fig. 6d). Although there were no bleaching reports in 1998 from the mainland of China, ages U/Th dated from samples of Yongshu Reef and Meiji Reef of Nansha Islands have revealed smaller $1999 \mathrm{AD}$ mortality probability peak for Yongshu than that for Meiji (Yu et al., 2012). Satellite data reveal that maximum TSA DHW in 1998 was about $7{ }^{\circ} \mathrm{C}$-weeks and more than $8^{\circ} \mathrm{C}$ weeks on Yongshu Reef and Meiji Reef, respectively, suggesting that bleaching of Yongshu Reef tended to be less severe and may contribute to the above difference. The second most anomalous event occurred in 2007 due to SST warm anomalies. Sixty-four percent of reefs are estimated to experience thermal stress (Fig. 6a) while thirty-two percent of reefs may experience bleaching-level thermal stress in 2007 (Fig. 6b). Intensity of mild bleaching-level thermal stress in 2007 had smaller difference with that in 1998 and both may be about 30\% reefs affected in the study area (Fig. 6c). However, only several reefs are likely to experience severe bleaching-level thermal stress in 2007, far less severe than that in 1998 (Fig. 6d). In June 2007, bleaching events were observed on Zhubi Reef and Meiji Reef of Nansha Islands (Li et al., 2011) when NOAA DHW and TSA_DHW here were both less than $3{ }^{\circ} \mathrm{C}$-weeks. If the DHW threshold of $4^{\circ} \mathrm{C}$-weeks based on satellite data really underestimates the extent and intensity of coral bleaching in SCS, corals affected in these two years might be tremendous especially in 1998. These potential intensities are estimated based on satellite data. In contrast to this bleak estimation, reef and coral can develop the abilities of acclimatization or adaptation to survive under different conditions. The mortality and bleaching in anomaly years may vary among sites, islands, island size, the presence of lagoon, windward or leeward exposure (Obura and Mangubhai, 2011) and taxa (Baird and Marshall, 2002; McClanahan et al., 2004; Prada et al., 2010; Furby et al., 2013).

Anomaly years are extracted based on ten percentages of reefs estimated to be affected by bleaching-level thermal stress: 1987, 1998, 2001, 2002, and 2007 (Fig. 6b). These years of 1987, 1998, and 2007 all match the subsequent year of the El Niño year, while 2002 is an El Niño year. The thermal stress in 2001 may be attributed to the elevated and warmer-than-normal SST after the 1998-2000 La Niña event. Historical coral mortality events in SCS also seemed correlating well in time with the warm periods of ENSO (Yu et al., 2012). However, the intensity of thermal stress also varies from anomaly year. The influences of bleaching-level thermal stress in 1987, 2001 and 2002 were less severe compared with that in 1998 and 2007 (Fig. 6b) due to not enough accumulation of positive sea surface temperature anomalies. Therefore, most severe thermal stress events appear to occur during the subsequent year of the El Niño year in the SCS.

\subsection{Anomaly durations}

Intensities of bleaching-level thermal stress and durations in anomaly years extracted by satellite products in CoRTAD for the whole SCS and for sub-regions are shown in Fig. 7. Durations vary considerably by year and by sub-region (Fig. 7). Nearly all the sub-regions are likely to experience the highest bleaching-level thermal stress in 1998 (Fig. 7c) and duration of thermal stress in 1998, on average, was likely to be 5 weeks for all the coral reefs in the study area (Fig. 7a). It is two weeks longer than the duration previously estimated from all the coral reefs in SCS (Selig et al., 2010). Sub-regions from B to E seem to be the most affected during this very strong El Niño and their durations are averaged approximately 4, 4, 5 and 6 weeks, respectively (Fig. 7c). In 2007, TSA duration was averaged 2 weeks (Fig. 7a). The short duration in this year may be 

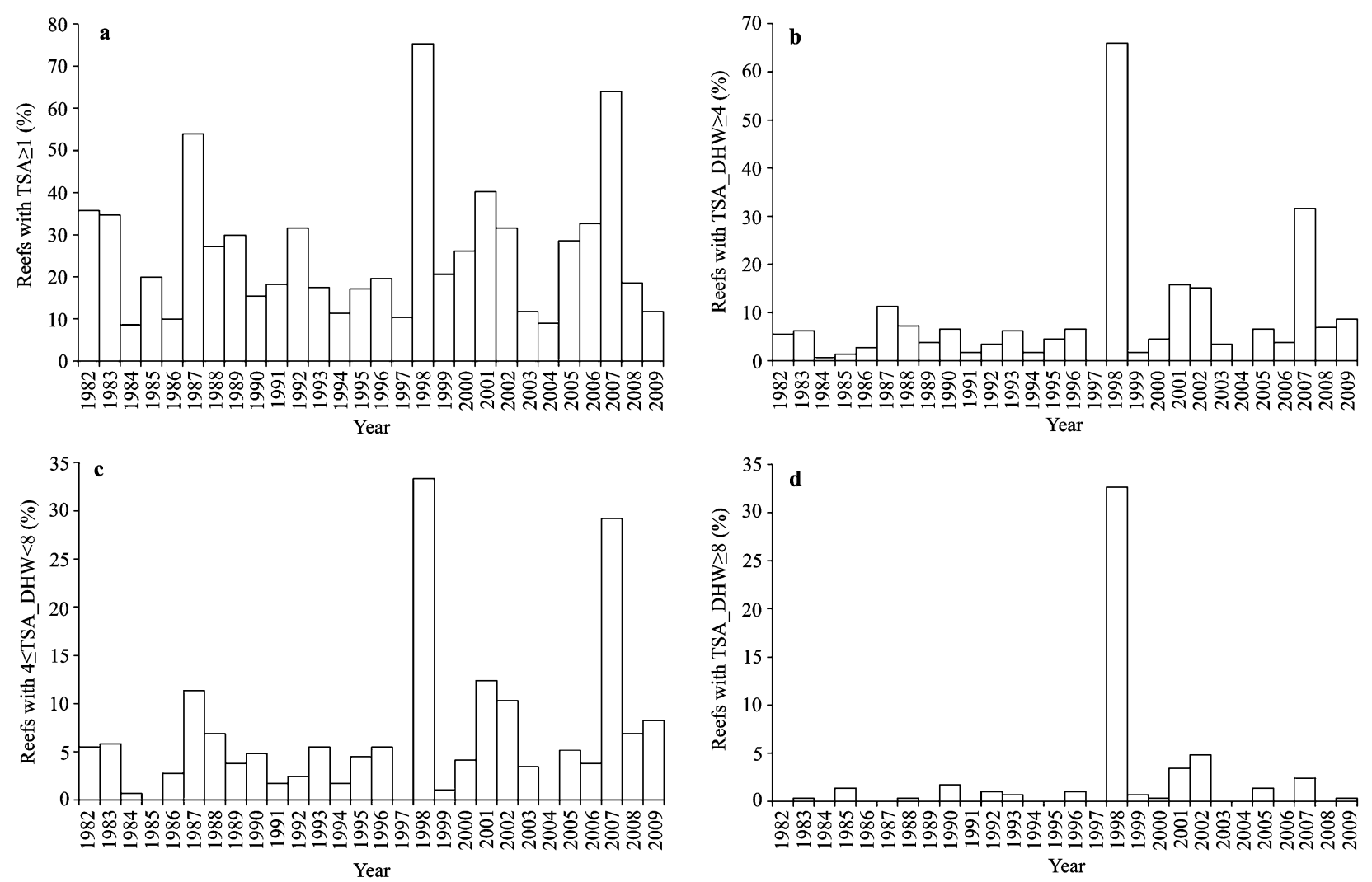

Fig. 6 Annual intensity of thermal stress during 1982-2009 calculated based on annual percentages of reefs reaching thermal stress thresholds of TSA $\geq 1$ (a), TSA_DHW $\geq 4$ (b), $4 \leq$ TSA_DHW $<8$ (c) and TSA_DHW $\geq 8$ (d), indicating potential intensity of thermal stress (regardless of severity), bleaching-level thermal stress, mild bleaching-level thermal stress and severe bleaching-level thermal stress, respectively

the main factor of less severity compared with the influences in 1998 (Fig. 7a). Durations of thermal stress in sub-regions $\mathrm{B}$ and $\mathrm{C}$ were averaged about 4 and 3 weeks, respectively, higher than other clusters in 2007 (Fig. 7f). Thus, most of the bleaching-level thermal stress in 2007 may exist across the northern SCS (sub-regions B and C) with more percentages of reefs estimated to be affected than in the southern SCS (sub-regions D to F) (Fig. 7f). The above analysis is based on the two extreme thermal stress anomaly years. Overall, reefs in clusters $\mathrm{B}$ and $\mathrm{E}$ tend to have more frequent occurrences of bleaching related thermal stress in anomaly years. Coral reefs in clusters C and D may be affected only in strong anomaly years and reefs in cluster $\mathrm{F}$ is the least frequent (Fig. 7).

\section{Conclusions}

Increases in SST are widely recognized as the most serious threat to coral reefs. In our study, we provided a spatio-temporal analysis of the past unknown thermal stress to China's coral reefs in SCS on the basis of 4-km high resolution satellite products in the CoRTAD. Results show that the variability of summer mean SST (May to September) from 1982 to 2009 in SCS shows an average upward trend of $0.2^{\circ} \mathrm{C} /$ decade. The waters of Xisha Islands and Dongsha Islands of the northern SCS are warming faster through time compared to the Zhongsha Islands and Nansha Islands sea areas of the southern SCS. Moreover, the southern part of Nansha Islands sea area also show a higher warming rate like the northern SCS. High frequency area of bleaching related thermal stress for these reefs is likely to concentrate in the area to the northwest of Luzon Island. Most of the severe thermal stress events during this period may occur during the subsequent year of the El Niño year.

There are areas in the northern portion of the SCS (seas of Xisha Islands and Dongsha Islands) that have faster warming rates accompanied with less frequent 

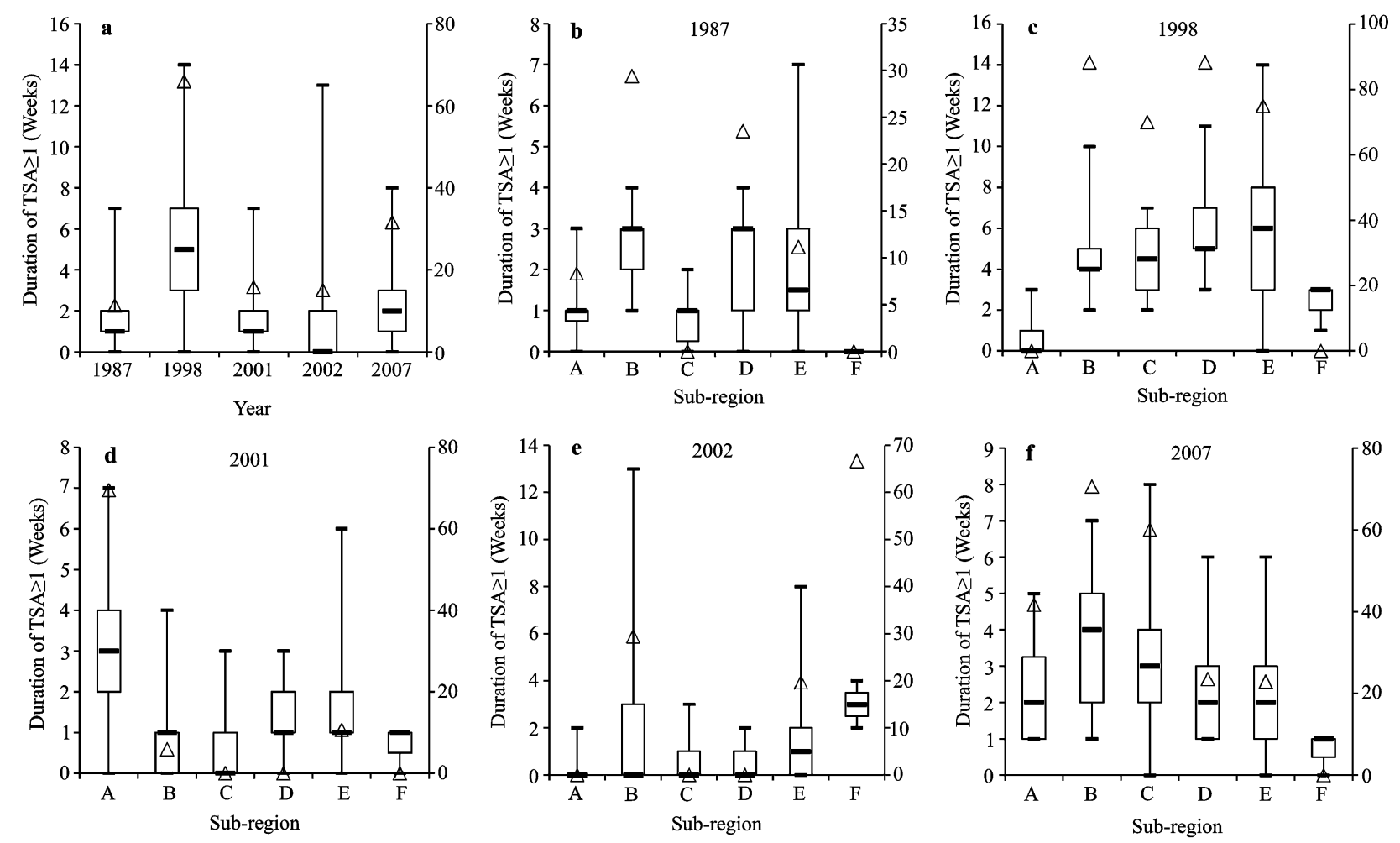

Fig. 7 Primary axis of box plot (median, percentiles and outliers) shows cumulative number of weeks with TSA $\geq 1$ during extracted anomaly years (a) and for sub-regions in each anomaly year (b-f). Annual percentages of reefs reaching thermal stress threshold of TSA_DHW $\geq 4$ are plotted on secondary axis with label of triangle

annual SST fluctuations but are affected by significant levels of thermal stress. Corals in these areas tend to be more susceptible to future bleaching unless they can develop mechanism to cope with the fast increase in SST. Some areas have frequent annual SST fluctuations and thermal stress events yet exhibit lower warming rates as in the northern part of the Nansha Islands sea area. Corals in these regions may be more adapted to positive SST anomalies and these areas may warm slower in the next few decades. However, there are also areas as in the case of the southern part of the Nansha Islands waters that have frequent annual SST fluctuations and thermal stress events, but show rapid warming. The ability of acclimation or adaptation of corals located in these seas needs further investigation. Corals in coastal areas (Hainan Island and Taiwan in China) also afford natural protection so that a rapid coral recovery can be achieved to better cope with the future thermal stress events. Besides, it is necessary to monitor reef health under thermal stress in an attempt to validate the estimation by satellite data and protect these reefs. Our results may provide insight into these surveys following ocean warming and ENSO events.

\section{Acknowledgements}

The datasets of SST and thermal stress used in this study are obtained from Coral Reef Temperature Anomaly Database. The authors are grateful to the reviewers for their valuable constructive comments.

\section{References}

Aeby G S, Williams G J, Franklin E C et al., 2011. Patterns of coral disease across the Hawaiian archipelago: relating disease to environment. PLoS ONE, 6(5): e20370. doi: 10.1371/journal.pone. 0020370

Allen G R, Werner T B, 2002. Coral reef fish assessment in the 'coral triangle' of southeastern Asia. Environmental Biology of Fishes, 65: 209-214. doi: 10.1023/A:1020093012502

Anthony K R N, Kline D I, Diaz-Pulido G et al., 2008. Ocean acidification causes bleaching and productivity loss in coral reef builders. Proceedings of the National Academy of Sciences of the United States of America, 105(45): 17442-17446. doi: 10.1073/pnas.0804478105

Arceo H O, Quibilan M C, Aliño P M et al., 2001. Coral bleach- 
ing in Philippine reefs: coincident evidences with mesoscale thermal anomalies. Bulletin of Marine Science, 69(2): 579-593.

Arthur D, Vassilvitskii S, 2007. k-means++: the advantages of careful seeding. Proceedings of the 18th Annual ACM-SIAM Symposium on Discrete Algorithms. SODA 2007, 1027-1035.

Baird A H, Marshall P A, 2002. Mortality, growth and reproduction in scleractinian corals following bleaching on the Great Barrier Reef. Marine Ecology Progress Series, 237: 133-141. doi: 10.3354/meps 237133

Berkelmans R, De'ath G, Kininmonth S et al., 2004. A comparison of the 1998 and 2002 coral bleaching events on the Great Barrier Reef: spatial correlation, patterns, and predictions. Coral Reefs, 23: 74-83. doi: 10.1007/s00338-003-0353-y

Burke L, Selig E, Spalding M, 2006. Reefs at Risk in Southeast Asia. Washington D C: World Resources Institute Press, 48.

Carilli J E, Norris R D, Black B et al., 2010. Century-scale records of coral growth rates indicate that local stressors reduce coral thermal tolerance threshold. Global Change Biology, 16: 1247-1257. doi: 10.1111/j.1365-2486.2009.02043.x

Carricart-Ganivet J P, Cabanillas-Terán N, Cruz-Ortega I et al., 2012. Sensitivity of calcification to thermal stress varies among genera of massive reef-building corals. PLoS ONE, 7(3): e32859. doi: 10.1371/journal.pone.0032859

Carrigan A D, Puotinen M L, 2011. Assessing the potential for tropical cyclone induced sea surface cooling to reduce thermal stress on the world's coral reefs. Geophysical Research Letters, 38: L23604. doi: 10.1029/2011GL049722

Casey K S, Brandon T B, Cornillon P et al., 2010. The past, present and future of the AVHRR Pathfinder SST program. In: Barale V et al. (eds.). Oceanography from Space: Revisited. New York: Springer Press, 273-287.

Chang Genying, Huang Fupeng, Li Man et al., 2012. Public perception of climate change and their support of climate policy in China: based on global surveys and in comparison with USA. Scientia Geographica Sinica, 32(12): 1481-1487. (in Chinese)

Chen T, Li S, Yu K et al., 2013. Increasing temperature anomalies reduce coral growth in the Weizhou Island, northern South China Sea. Estuarine, Coastal and Shelf Science, 130: 121-126. doi: 10.1016/j.ecss.2013.05.009

Dai C F, Fan T Y, Wu C S, 1995. Coral fauna of Tungsha Tao (Pratas Islands). Acta Oceanographica Taiwanica, 34: 1-16.

Dai Changfeng, 2010. Biotic reefs and reef biotops in Taiwan area. Journal of Palaeogeography, 12(5): 565-576. (in Chinese)

Fan T Y, Wei C, Fang L S, 2008a. Status of coral reef communities and reef restoration efforts at Dongsha Atoll, South China Sea. Available at: http://www.nova.edu/ncri/11icrs/abstract files/icrs2008-000339.pdf

Fan T Y, Wu B J, Fang L S, 2008b. The heterogeneity of temperature change and coral bleaching during temperature abnormally warm in summer 2007. Available at: http://www. nova.edu/ncri/11icrs/abstract_files/icrs2008-000308.pdf

Fang G, Chen H, Wei Z et al., 2006. Trends and interannual vari- ability of the South China Sea surface winds, surface height, and surface temperature in the recent decade. Journal of Geophysical Research, 111: C11S16. doi: 10.1029/2005JC003276

Ferreira B P, Costa M B S F, Coxey M S et al., 2013. The effects of sea surface temperature anomalies on oceanic coral reef systems in the southwestern tropical Atlantic. Coral Reefs, 32: 441-454. doi: 10.1007/s00338-012-0992-y

Fu Xiumei, Wang Changyun, Shao Changlun et al., 2009. Investigation of the status of coral reef resources and medicinal research in China. I. coral reef resources and ecological functions. Periodical of Ocean University of China, 39(4): 676684. (in Chinese)

Furby K A, Bouwmeester J, Berumen M L, 2013. Susceptibility of central Red Sea corals during a major bleaching event. Coral Reefs, 32: 505-513. doi: 10.1007/s00338-012-0998-5

Glynn P W, 1993. Coral reef bleaching: ecological perspectives. Coral Reefs, 12: 1-17. doi: 10.1007/BF00303779

Glynn P W, Cortés-Núñez J, Guzmán-Espinal H M et al., 1988. El Niño (1982-83) associated coral mortality and relationship to sea surface temperature deviations in the tropical eastern Pacific. Proceedings of the 6th International Coral Reef Symposium. Townsville, Australia, 3: 231-243.

Goreau T J, Hayes R L, 1994. Coral bleaching and ocean 'hot spots'. Ambio, 23: 176-180.

Goreau T, McClanahan T, Hayes R et al., 2000. Conservation of coral reefs after the 1998 global bleaching event. Conservation Biology, 14(1): 5-15. doi: 10.1046/j.1523-1739.2000.00011.x

Guest J R, Baird A H, Maynard J A et al., 2012. Contrasting patterns of coral bleaching susceptibility in 2010 suggest an adaptive response to thermal stress. PLoS ONE, 7(3): e33353. doi: 10.1371/journal.pone.0033353

Heron S F, Willis B L, Skirving W J et al., 2010. Summer hot snaps and winter conditions: modelling white syndrome outbreaks on Great Barrier Reef corals. PLoS ONE, 5(8): e12210. doi: 10.1371/journal.pone.0012210

Hoegh-Guldberg O, 1999. Climate change, coral bleaching and the future of the world's coral reefs. Marine Freshwater Research, 50: 839-866. doi: 10.1071/MF99078

Hongo C, Yamano H, 2013. Species-specific responses of corals to bleaching events on anthropogenically turbid reefs on Okinawa Island, Japan, over a 15-year period (1995-2009). PLoS ONE, 8(4): e60952. doi: 10.1371/journal.pone.0060952

Huang Zhuo, Xu Haiming, Du Yan et al., 2009. Two sea-surface warming events in the South China Sea during and after El Niño. Journal of Tropical Oceanography, 28(5): 49-55. (in Chinese)

Hughes T P, Huang H, Young M A L, 2012. The wicked problem of China's disappearing coral reefs. Conservation Biology, 27(2): 261-269. doi: 10.1111/j.1523-1739.2012.01957.x

IPCC (Intergovernmental Panel on Climate Change), 2013. Climate change 2013: the physical science basis. In: Stocker T F et al. (eds.). Contribution of Working Group I to the Fifth Assessment Report of the Intergovernmental Panel on Climate Change. Cambridge: Cambridge University Press.

Kerr R A, 1999. Big El Niños ride the back of slower climate 
change. Science, 283(5405): 1108-1109. doi: 10.1126/science. 283.5405.1108

Klein S A, Brian J S, Ngar-Cheung L, 1999. Remote sea surface temperature variations during ENSO: evidence for a tropical atmospheric bridge. Journal of Climate, 12: 917-932. doi: 10.1175/1520-0442(1999)012<0917:RSSTVD>2.0.CO;2

Kleypas J A, McManus J W, Menez L A B, 1999. Environmental limits to coral reef development: where do we draw the line? American Zoologist, 39(1): 146-159. doi: 10.1093/icb/39.1. 146

Langdon C, Takahashi T, Sweeney C et al., 2000. Effect of calcium carbonate saturation state on the calcification rate of an experimental coral reef. Global Biogeochemical Cycles, 14(2): 639-654. doi: 10.1029/1999GB001195

Li S, Yu K F, Chen T R et al., 2011. Assessment of coral bleaching using symbiotic zooxanthellae density and satellite remote sensing data in the Nansha Islands, South China Sea. Chinese Science Bulletin, 56(10): 1031-1037. doi: 10.1007/s11434011-4390-6

Li X, Liu S, Huang H et al., 2012. Coral bleaching caused by an abnormal water temperature rise at Luhuitou fringing reef, Sanya Bay, China. Aquatic Ecosystem Health \& Management, 15(2): 227-233. doi: 10.1080/14634988.2012.687651

Liu G, Strong A E, Skirving W, 2003. Remote sensing of sea surface temperatures during 2002 Barrier Reef coral bleaching. Eos, Transactions American Geophysical Union, 84(15): 137-144. doi: 10.1029/2003EO150001

Liu Y, Liu W, Peng Z et al., 2009. Instability of seawater $\mathrm{pH}$ in the South China Sea during the mid-late Holocene: evidence from boron isotopic composition of corals. Geochimica et Cosmochimica Acta, 73: 1264-1272. doi: 10.1016/j.gca.2008. 11.034

Logan C A, Dunne J P, Eakin C M et al., 2014. Incorporating adaptive responses into future projections of coral bleaching. Global Change Biology, 20(1): 125-139. doi: 10.1111/gcb. 12390

Lough J M, 2000. 1997-98: unprecedented thermal stress to coral reefs? Geophysical Research Letters, 27(23): 3901-3904. doi: 10.1029/2000GL011715

Lough J M, 2012. Small change, big difference: sea surface temperature distributions for tropical coral reef ecosystems, 1950-2011. Journal of Geophysical Research, 117: C09018. doi: 10.1029/2012JC008199

Ma Guangren, 2012. Valuing wetlands as natural infrastructure to safeguard human development. Wetland Science, 10(4): 385-388. (in Chinese)

McClanahan T R, Baird A H, Marshall P A et al., 2004. Comparing bleaching and mortality responses of hard corals between southern Kenya and the Great Barrier Reef, Australia. Marine Pollution Bulletin, 48: 327-335. doi: 10.1016/j.marpolbul. 2003.08.024

McManus J W, 1994. The Sprately Islands: a marine park? AMBIO, 23: 181-186.

McWilliams J P, Côté I M, Gill J A et al., 2005. Accelerating impacts of temperature-induced coral bleaching in the Carib- bean. Ecology, 86(8): 2055-2060. doi: 10.1890/04-1657

Meissner K J, Lippmann T, Gupta A S, 2012. Large-scale stress factors affecting coral reefs: open ocean sea surface temperature and surface seawater aragonite saturation over the next 400 years. Coral Reefs, 31: 309-319. doi: 10.1007/s00338011-0866-8

Moberg F, Folke C, 1999. Ecological goods and services of coral reef ecosystems. Ecological Economics, 29: 215-233. doi: 10.1016/S0921-8009(99)00009-9

Mora C, Ginsburg R, 2007. A clear human footprint on the Caribbean coral reefs. Proceedings of the Royal Society B, 275: 767-773. doi: 10.1098/rspb.2007.1472

Morton B, Blackmore G, 2001. South China Sea. Marine Pollution Bulletin, 42(12): 1236-1263. doi: 10.1016/S0025-326X (01)00240-5

Negri A P, Flores F, Röthig T et al., 2011. Herbicides increase the vulnerability of corals to rising sea surface temperature. Limnology and Oceanography, 56(2): 471-485. doi: 10.4319/lo. 2011.56.2.0471

Negri A P, Hoogenboom M O, 2011. Water contamination reduces the tolerance of coral larvae to thermal stress. PLoS ONE, 6(5): e19703. doi: 10.1371/journal.pone.0019703

Obura D, Mangubhai S, 2011. Coral mortality associated with thermal fluctuations in the Phoenix Islands, 2002-2005. Coral Reefs, 30: 607-619. doi: 10.1007/s00338-011-0741-7

Peñaflor E L, Skirving W J, Strong A E et al., 2009. Sea-surface temperature and thermal stress in the Coral Triangle over the past two decades. Coral Reefs, 28: 841-850. doi: 10.1007/ s00338-009-0522-8

Podestá G P, Glynn P W, 2001. The 1997-98 El Niño event in Panama and Galápagos: an update of thermal stress indices relative to coral bleaching. Bulletin of Marine Science, 69(1): 43-59.

Prada C, Weil E, Yoshioka P M, 2010. Octocoral bleaching during unusual thermal stress. Coral Reefs, 29: 41-45. doi: 10.1007/ s00338-009-0547-z

Randall C J, Szmant A M, 2009. Elevated temperature affects development, survivorship, and settlement of the elkhorn coral, Acropora palmata (Lamarck 1816). The Biological Bulletin, 217(3): 269-282. doi: 10.1143/JJAP.43.5922

Selig E R, Casey K S, Bruno J F, 2010. New insights into global patterns of ocean temperature anomalies: implications for coral reef health and management. Global Ecology and Biogeography, 19: 397-411. doi: 10.1111/j.1466-8238.2009. 00522.x

Shang Erping, Bai Wanqi, 2012. A review on the studies of wetland vulnerability assessment. Wetland Science, 10(3): 378384. (in Chinese)

Soong K, Dai C F, Lee C P, 2002. Status of Pratas Atoll in South China Sea. Proceedings of the 4th Conference on the Protected Areas of East Asia. Taipei, 739-742.

Toscano M A, Liu G, Guch I C et al., 2000. Improved prediction of coral bleaching using high-resolution HotSpot anomaly mapping. 9th International Coral Reef Symposium. Bali, Indonesia, 2: 1143-1147. 
Wang C, Wang W, Wang D et al., 2006. Interannual variability of the South China Sea associated with El Niño. Journal of Geophysical Research, 111: C03023. doi: 10.1029/2005JC003333

Weeks S J, Anthony K R N, Bakun A et al., 2008. Improved predictions of coral bleaching using seasonal baselines and higher spatial resolution. Limnology and Oceanography, 53(4): 1369-1375. doi: 10.4319/1o.2008.53.4.1369

Wilkinson C, 1998. The 1997-1998 mass bleaching event around the world. In: Wilkinson C et al. (eds.). Status of Coral Reefs of the World: 1998. Townsville: Australian Institute of Marine Science Press, 12.

Worum F P, Carricart-Ganivet J P, Benson L et al., 2007. Simulation and observations of annual density banding in skeletons of Montastraea (Cnidaria: Scleractinia) growing under thermal stress associated with ocean warming. Limnology and Oceanography, 52(5): 2317-2323. doi: 10.4319/10.2007.52.5.2317

Yu K F, 2012. Coral reefs in the South China Sea: their response to and records on past environmental changes. Science China Earth Sciences, 55(8): 1217-1229. doi: 10.1007/s11430-012-
4449-5

Yu K F, Zhao J X, Liu T S et al., 2004. High-frequency winter cooling and reef coral mortality during the Holocene climatic optimum. Earth and Planetary Science Letters, 224: 143-155. doi: 10.1016/j.epsl.2004.04.036

Yu K, Zhao J, Shi Q et al., 2012. Recent massive coral mortality events in the South China Sea: was global warming and ENSO variability responsible? Chemical Geology, 320-321: 54-65. doi: 10.1016/j.chemgeo.2012.05.028

Zhang Yaoguang, Liu Kai, Liu Guichun, 2012. The evolvement of the state maritime boundary in South China Sea by maps: China's nine-dotted maritime boundary line in South China Sea. Scientia Geographica Sinica, 32(9): 1033-1040. (in Chinese)

Zhao M X, Yu K F, Zhang Q M et al., 2014. Age structure of massive Porites lutea corals at Luhuitou fringing reef (northern South China Sea) indicates recovery following severe anthropogenic disturbance. Coral Reefs, 33: 39-44. doi: 10.1007/ s00338-013-1109-y 